\title{
Bias in genomic predictions by mating practices for linear type traits in a large-scale genomic evaluation
}

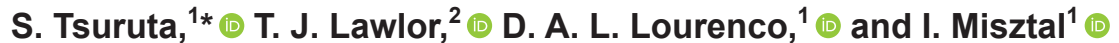 \\ ${ }^{1}$ Animal and Dairy Science Department, University of Georgia, Athens 30602 \\ ${ }^{2}$ Holstein Association USA Inc., Brattleboro, VT 05301
}

\begin{abstract}
The objective of this study was to clarify how bias in genomic predictions is created by investigating a relationship among selection intensity, a change in heritability $\left(\Delta h^{2}\right)$, and assortative mating (ASM). A change in heritability, resulting from selection, reflects the impact that the Bulmer effect has on the reduction in between-family variation, whereas assortative mating impacts the within-family variance or Mendelian sampling variation. A partial data set up to 2014, including $841 \mathrm{~K}$ genotyped animals, was used to calculate genomic predictions with a single-step genomic model for 18 linear type traits in US Holsteins. A full data set up to 2018, including 2.3 million genotyped animals, was used to calculate benchmark genomic predictions. Inbreeding and unknown parent groups for missing parents of animals were included in the model. Genomic evaluation was performed using 2 different genetic parameters: those estimated $14 \mathrm{yr}$ ago, which have been used in the national genetic evaluation for linear type traits in the United States, and those newly estimated with recent records from 2015 to 2018 and those corresponding pedigrees. Genetic trends for 18 type traits were estimated for bulls with daughters and cows with phenotypes in 2018. Based on selection intensity and mating decisions, these traits can be categorized into 3 groups: (a) high directional selection, (b) moderate selection, and (c) intermediate optimum selection. The first 2 categories can be explained by positive assortative mating, and the last can be explained by negative assortative or disassortative mating. Genetic progress was defined by genetic gain per year based on average standardized genomic predictions for cows from 2000 to 2014. Traits with more genetic progress tended to have more "inflated" genomic predictions (i.e., "inflation" means here that genomic predictions are larger in absolute values than expected, whereas "deflation"
\end{abstract}

Received April 6, 2020.

Accepted August 19, 2020.

*Corresponding author: shogo@uga.edu means smaller than expected). Heritability estimates for 14 out of 18 traits declined in the last $16 \mathrm{yr}$, and $\Delta h^{2}$ ranged from -0.09 to 0.04 . Traits with a greater decline in heritability tended to have more deflated genomic predictions. Biases (inflation or deflation) in genomic predictions were not improved by using the latest genetic parameters, implying that bias in genomic predictions due to preselection was not substantial for a large-scale genomic evaluation. Moreover, the strong selection intensity was not fully responsible for bias in genomic predictions. The directional selection can decrease heritability; however, positive assortative mating, which was strongly associated with large genetic gains, could minimize the decline in heritability for a trait under strong selection and could affect bias in genomic predictions.

Key words: heritability changes, assortative mating, US Holsteins

\section{INTRODUCTION}

Primary reasons for biases in genomic predictions (GEBV) with a single-step genomic (ssG)BLUP were reported by Tsuruta et al. (2019) for 18 linear type traits in US Holsteins. These biases can be defined as inflation or deflation in predictions and deviations of predictions from the true or expected values. In this study, inflation (deflation) is defined as larger (smaller) genomic predictions in absolute values compared with expected GEBV. One main reason for this scale change was incompatibility between a pedigree-based relationship matrix (A) and a genomic relationship matrix (G). This incompatibility can be created by preselection of genotyped animals (Patry and Ducrocq, 2011; Vitezica et al., 2011; Tyrisevä et al., 2018), especially in the early stage of the genomic era (i.e., the period of a few years after 2008 for US dairy cattle). In those years, young sons of strongly selected top proven sires, as well as old elite bulls born before 2008, were genotyped. Another reason was an improper definition of unknown parent groups (UPG) assigned for missing parents (Bradford et al., 2019; Tsuruta et al., 2019). When 
animals with no phenotypes or few animals are assigned to UPG, the UPG cannot be accurately estimated. After introducing inbreeding in $\mathbf{A}$ for all animals and $\mathbf{G}$ for genotyped animals and assigning a proper UPG, the bias (inflation/deflation) in GEBV for young genotyped bulls was dramatically reduced, but some bias in each trait still remained (Tsuruta et al., 2014). An additional reason could be that heritability $\left(h^{2}\right)$ and genetic correlations used in the national genetic evaluation for the 18 type traits may not reflect the current US Holstein population because of long-time genomic selection under positive or negative assortative mating, which can significantly change allele frequencies and withinfamily genetic variances. Today, more genotypes have been accumulated for dairy cattle in the United States and are available for evaluations; thus, the effect of assortative mating may be more evident. Linear type traits in US Holsteins can be a desirable data set for genomic research because of the different selection intensities and mating practices that are exhibited. Each linear type trait may have a different direction for selection and a different mating pattern. Therefore, the use of a selection index with multiple traits in mating programs can prevent extreme assortative mating. These traits allow us to see the effect that selection and mating decisions have on genetic variances, covariances, and model validation. Under an infinitesimal model, selection through the well-known Bulmer effect reduces the between-family variation in the population (Bulmer, 1971). Assuming a finite number of genes, as we do with genomic selection, the impact of selection and mating can be larger. Genomic selection reduces the variance of the sum of the marker effects (Van Grevenhof et al., 2012), which reduces the overall additive genetic variance. Additionally, genomic selection can cause an increase in the homozygosity and linkage disequilibrium among desirable markers and increase the covariance between parents (Bonk et al., 2016). A reduction in the within-family variance can be measured by the classical formula $\frac{1}{4}\left(1-\mathrm{F}_{\mathrm{S}}\right) \sigma_{a}^{2}+\frac{1}{4}\left(1-\mathrm{F}_{\mathrm{D}}\right) \sigma_{a}^{2}$, where $\mathrm{F}_{\mathrm{S}}$ and $\mathrm{F}_{\mathrm{D}}$ are the pedigree-based inbreeding coefficients of sires and dams, and $\sigma_{a}^{2}$ is the original additive genetic variance (Falconer and Mackay, 1996). Bonk et al. (2016) extended this formula to genomic data using $\mathrm{F}$ as a measure of marker homozygosity. In this study, we defined assortative mating (ASM) calculated by a correlation between GEBV of mates, which can be interpreted as a measure of marker homozygosity evolution, using a retrospective approach.

The objective of this study was to clarify how bias in genomic predictions was created by investigating relationships among selection intensity, a change in heritability $\left(\Delta h^{2}\right)$, and ASM, which may provide valuable insight into the reasons for the change in genetic (co)variances and their effects on the unbiasedness of genomic predictions. The $\Delta h^{2}$ resulting from selection reflects the impact that the Bulmer effect has on the reduction in between-family variation, whereas ASM impacts the within-family genetic variance or Mendelian sampling variation.

\section{MATERIALS AND METHODS}

\section{Data}

Holstein data from the national genetic evaluation in December 2018 for 18 linear type traits were provided by the Holstein Association USA Inc. (Brattleboro, VT). First, the data were split into 5 year-base subsets: 1999-2002 (1,011,288 records for 823,123 cows and 2,152,328 animals in pedigree), 2003-2006 (944,730 records for 754,362 cows and 2,008,825 animals in pedigree), 2007-2010 (1,036,076 records for 830,438 cows and 2,106,856 animals in pedigree), 2011-2014 (945,695 records for 763,849 cows and 1,971,719 animals in pedigree), and 2015-2018 (789,898 records for 655,165 cows and $1,770,409$ animals in pedigree). Whereas phenotypic records were truncated in each period as above, all pedigree information related to those animals with phenotypes was used. Thereafter, (co)variance component estimation was conducted for each data set with a repeatability animal model as described in Tsuruta et al. (2002).

For full genomic evaluation in 2018, all available data, including 10,946,264 phenotypes recorded from 1983 to 2018 for 7,216,767 cows and 13,591,145 animals in pedigree, were used (Table 1). In addition, we used 2,334,951 animals genotyped as of December 2018 provided by the Council on Dairy Cattle Breeding (Bowie, MD), and all genotypes were imputed to 79,294 SNP markers. Table 1 also describes numbers of phenotypes, genotypes, and animals for the 2014 data set, which was used for genomic evaluation in 2014. Figure 1 shows numbers of genotyped Holstein males and those with daughters. The number of genotyped Holstein males rapidly increased until 2014 but moderated up to 2018, possibly because late-born 2018 animals could have their data added to the database in the following year (2019). The average percentage of genotyped bulls with daughters having phenotypes decreased from $16.0 \%$ in 2014 to $8.6 \%$ in 2018 , which means that more young bulls and sons of those young bulls were recently genotyped before they had daughters. It also suggests that those young genotyped sons were not strongly preselected because they were not out of proven sires. As a result, more genotyped young bulls will be culled in the 


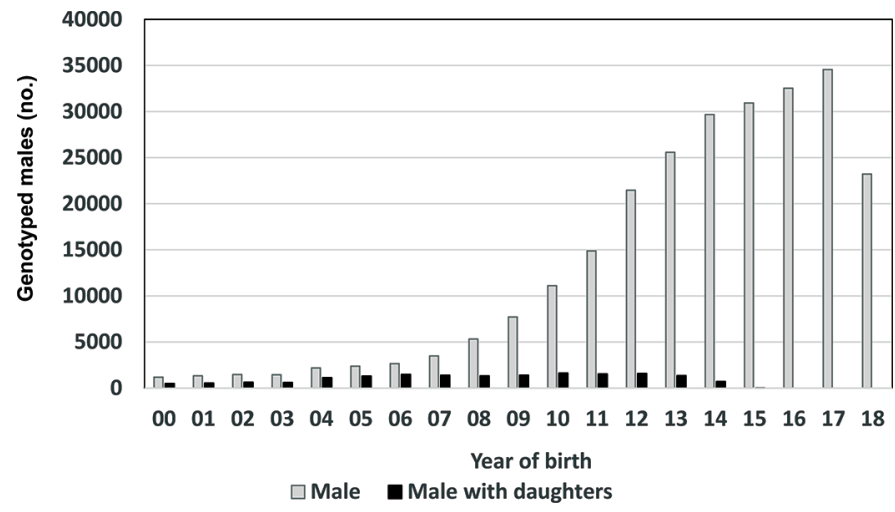

Figure 1. Numbers of genotyped Holstein males by year of birth from 2000 to 2018 (00 to 18).

future (i.e., stronger post-selection for proven bulls). Figure 2 shows numbers of genotyped Holstein females and those with phenotypes. The number of genotyped Holstein females (mainly heifers) rapidly increased until 2017. The average percentage of cows with phenotypes also decreased, from 18.2 to $8.3 \%$, which means that more heifers were recently genotyped. As a result, more heifers (i.e., more than $90 \%$ of genotyped heifers) may

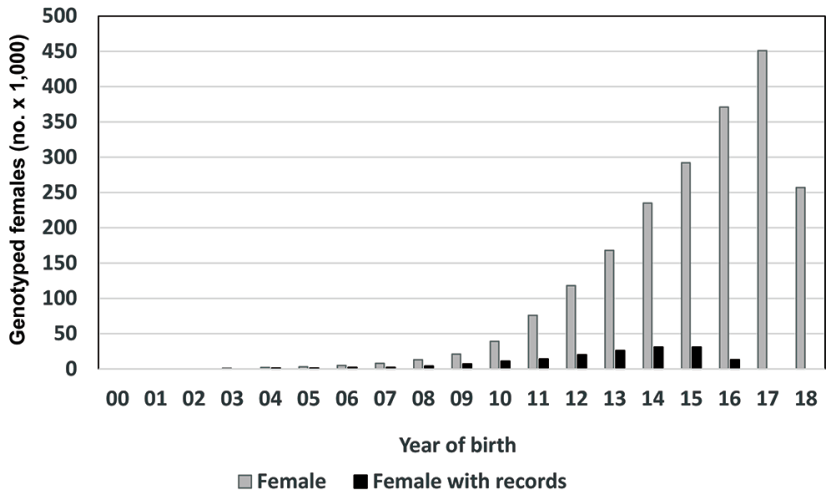

Figure 2. Numbers of genotyped Holstein females by year of birth from 2000 to 2018 (00 to 18 ).

not have had phenotypes for type traits in the future although some of them may have had phenotypes for production traits. Many heifers, especially when genotyped at younger age, may not have survived for several reasons (e.g., sold, disease, accident, death) until they received phenotypic records or by the end of the first lactation.

\section{Single-Step Genomic Model and Validation}

Including the inverse of the combined relationship matrix of the pedigree-based and genomic information as described in Legarra et al. (2009) and Aguilar et al. (2010), the single-step genomic model can be expressed as follows:

$$
\left[\begin{array}{ccc}
\mathbf{X}^{\prime} \mathbf{X} & \mathbf{X}^{\prime} \mathbf{Z} & \mathbf{X}^{\prime} \mathbf{W} \\
\mathbf{Z}^{\prime} \mathbf{X} & \mathbf{Z Z}+\mathbf{H}^{\prime-1} \alpha & \mathbf{Z}^{\prime} \mathbf{W} \\
\mathbf{W}^{\prime} \mathbf{X} & \mathbf{W}^{\prime} \mathbf{Z} & \mathbf{W}^{\prime} \mathbf{W}+\mathbf{I} \lambda
\end{array}\right]\left[\begin{array}{c}
\boldsymbol{\beta} \\
\mathbf{a} \\
\mathbf{p}
\end{array}\right]=\left[\begin{array}{c}
\mathbf{X}^{\prime} \mathbf{y} \\
\mathbf{Z}^{\prime} \mathbf{y} \\
\mathbf{W}^{\prime} \mathbf{y}
\end{array}\right]
$$

where $\mathbf{y}$ is the vector for observations, $\boldsymbol{\beta}$ is the vector for fixed effects, $\mathbf{a}$ is the vector for random additive genetic effects, $\mathbf{p}$ is the vector for random permanent environmental effects, $\mathbf{X}$ is the design matrix for fixed effects $\boldsymbol{\beta}, \mathbf{Z}$ is the design matrix for random effects $\mathbf{a}, \mathbf{W}$ is the design matrix for random effects $\mathbf{p}, \alpha$ is the variance ratio $\left(\frac{\sigma_{e}^{2}}{\sigma_{a}^{2}}\right)$ of the residual variance $\sigma_{e}^{2}$ and the additive genetic variance $\sigma_{a}^{2}, \lambda$ is the variance ratio $\left(\frac{\sigma_{e}^{2}}{\sigma_{p}^{2}}\right)$ of the residual variance $\sigma_{e}^{2}$ and the permanent environmental variance $\sigma_{p}^{2}$, $\mathbf{I}$ is the identity matrix, and $\mathbf{H}^{-1}$ is the inverse of the combined relationship matrix, as follows:

$$
\mathbf{H}^{-1}=\left[\begin{array}{cc}
\mathbf{A}^{11} & \mathbf{A}^{12} \\
\left(\mathbf{A}^{12}\right)^{\prime} & \mathbf{A}^{22}
\end{array}\right]+\left[\begin{array}{cc}
0 & 0 \\
0 & \left(\mathbf{G}^{-1}-\mathbf{A}_{22}^{-1}\right)
\end{array}\right]
$$

where $\mathbf{A}^{n n}$ is the inverse of the pedigree-based relationship matrix where $n=1$ indicates nongenotyped animals and $n=2$ indicates genotyped animals, $\mathbf{G}^{-1}$ is the inverse of the genomic relationship matrix, and $\mathbf{A}_{22}^{-1}$ is the 
inverse of the pedigree-based relationship matrix for genotyped animals. According to the result from Tsuruta et al. (2019), inbreeding was included in A (Aguilar and Misztal, 2008) and G. The G matrix (VanRaden, 2008) was constructed using $\mathbf{G}=\frac{\mathbf{U U}^{\prime}}{2 \sum p_{i}\left(1-p_{i}\right)}$, where $p_{i}$ is the observed allele frequency for SNP $i$ calculated based on all 2.3 million genotyped animals, and $\mathbf{U}$ is a centered matrix of SNP content. After that, $\mathbf{G}$ was rescaled based on $\mathbf{A}_{22}$ by means of diagonals and off-diagonals. There is no guarantee that $\mathbf{G}$ is nonsingular. To calculate $\mathbf{G}^{-1}$, we combined $95 \%$ of the original $\mathbf{G}$ and $5 \%$ of $\mathbf{A}_{22}$. These fractions were compromised values to keep high accuracy in GEBV and a good convergence rate in solving mixed model equations (MME); $\mathbf{G}=90 \%$ original $\mathbf{G}+$ $10 \% \mathbf{A}_{22}$ required fewer iterations but lost significant accuracy, and $\mathbf{G}=99 \%$ original $\mathbf{G}+1 \% \mathbf{A}_{22}$ had 0.01 higher accuracy but required 3 times more iterations.

As proposed in Tsuruta et al. (2019), UPG on sex (sire and dam) and birth-year group (every 4 yr for sire and every 2 yr for dam) were assumed to be fixed effects and considered only in the pedigree-based relationship matrices, using

$$
\left.\begin{array}{rl}
{\left[\mathbf{Z}^{\prime} \mathbf{Z}+\left[\begin{array}{cc}
\mathbf{A}^{11} & \mathbf{A}^{12} \\
\left(\mathbf{A}^{12}\right)^{\prime} & \mathbf{A}^{22}
\end{array}\right]+\left[\begin{array}{cc}
0 & 0 \\
0 & \left(\mathbf{G}^{-1}-\mathbf{A}_{22}^{-1}\right)
\end{array}\right]\right.} & -\left(\left[\begin{array}{cc}
\mathbf{A}^{11} & \mathbf{A}^{12} \\
\left(\mathbf{A}^{12}\right)^{\prime} & \left(\mathbf{A}^{22}-\mathbf{A}_{22}^{-1}\right)
\end{array}\right]\right) \\
& \mathbf{Q}^{\prime}\left(\left[\begin{array}{cc}
\mathbf{A}^{11} & \mathbf{A}^{12} \\
\left(\mathbf{A}^{12}\right)^{\prime} & \left(\mathbf{A}^{22}-\mathbf{A}_{22}^{-1}\right)
\end{array}\right]\right)
\end{array}\right]
$$

instead of

$$
\left.\begin{array}{rl}
\mathbf{Z}^{\prime} \mathbf{Z}+\left[\begin{array}{cc}
\mathbf{A}^{11} & \mathbf{A}^{12} \\
\left(\mathbf{A}^{12}\right)^{\prime} & \mathbf{A}^{22}
\end{array}\right]+\left[\begin{array}{cc}
0 & 0 \\
0 & \left(\mathbf{G}^{-1}-\mathbf{A}_{22}^{-1}\right)
\end{array}\right] & -\left(\left[\begin{array}{cc}
\mathbf{A}^{11} & \mathbf{A}^{12} \\
\left(\mathbf{A}^{12}\right)^{\prime} & \mathbf{A}^{22}
\end{array}\right]+\left[\begin{array}{cc}
0 & 0 \\
0 & \left(\mathbf{G}^{-1}-\mathbf{A}_{22}^{-1}\right)
\end{array}\right]\right) \mathbf{Q} \\
& \mathbf{Q}^{\prime}\left(\left[\begin{array}{cc}
\mathbf{A}^{11} & \mathbf{A}^{12} \\
\left(\mathbf{A}^{12}\right)^{\prime} & \mathbf{A}^{22}
\end{array}\right]+\left[\begin{array}{ll}
0 & 0 \\
0 & \left(\mathbf{G}^{-1}-\mathbf{A}_{22}^{-1}\right)
\end{array}\right]\right) \mathbf{Q}
\end{array}\right]
$$

where $\mathbf{Q}$ is the matrix that assigns UPG for genetic groups. In theory, when UPG is assigned for $\mathbf{A}$, genetic differences in $\mathbf{G}$ can be taken into account using the same UPG definition for A (Misztal et al., 2013). As described in Tsuruta et al. (2019), the main reason for ignoring $\mathbf{Q}^{\prime} \mathbf{G}^{-1} \mathbf{Q}$ was the extreme estimate for the last UPG, possibly caused by incompatibility among $\mathbf{A}, \mathbf{G}$, and $\mathbf{A}_{22}$. However, when $\mathbf{Q}^{\prime} \mathbf{G}^{-1} \mathbf{Q}$ was ignored, no extreme UPG was estimated. The MME can be solved as long as $\mathbf{A}^{22}-\mathbf{A}_{22}^{-1}$ is positive. This behavior (estimating extreme UPG) indicates that including both UPG for $\mathbf{A}$ and $\mathbf{G}$ in the model may have created an ill-conditioned structure (i.e., $\mathbf{A}^{22}+\mathbf{G}^{-1}-\mathbf{A}_{22}^{-1}$ or $\mathbf{A}^{22}-\mathbf{A}_{22}^{-1}$ is not positive definite). To avoid large biases in GEBV, this was a reasonable choice in this study; the issue is still under investigation at this time. Another choice could be the metafounder approach, which is similar to using random UPG (Legarra et al., 2015). When proper covariances or correlations among UPGs are estimated, UPG can be stably estimated. The metafounder or random UPG could be a practical method in the future but investigations using various field data sets are still needed. On the other hand, when the UPG was estimated as fixed effects, the estimates could be unstable as shown in this study, possibly due to sensitivity to the compatibility among relationship matrices.

Overall, 8.7 and $25.0 \%$ of sires and dams were unknown, respectively. Figure 3 shows frequencies of unknown parents for genotyped animals. Fewer than $1 \%$ of genotyped animals had unknown sires, whereas more than 10\% of recently genotyped animals had unknown dams.

Genomic predictions for the 18 type traits were calculated using phenotypes, pedigrees, and genotypes up to 2014. To validate genomic predictions for bulls that were young in the 2014 data, a full data set was used that in- 
cluded all phenotypes, pedigrees, and genotypes up to 2018. As indicators of inflation (or deflation) and reliability of GEBV, regression coefficients $\left(\mathbf{b}_{1}\right)$ and coefficients of determination $\left(\mathbf{R}^{2}\right)$ from the linear regression equation, daughter yield deviations (DYD) in $2018=\mathrm{b}_{0}+\mathrm{b}_{1} \times$ GEBV in 2014, were obtained (Mrode and Swanson, 2004), calculated from GEBV using the full data set up to 2018. For comparison, genomic parent averages (GPA) in 2014 were also used to calculate $\mathrm{b}_{1}$ and $\mathrm{R}^{2}$.

\section{Genetic Trends}

Genetic trends for 18 type traits were calculated by averaging genomic PTA (GPTA = half of GEBV) by year of birth. Each PTA was standardized by dividing by its additive genetic standard deviation (SD) to compare all traits on the same scale. Bulls with daughters having records in 2018 and cows with phenotypic records in 2018 were included in these genetic trends. The genetic base was set to the mean GPTA for cows with records born in 2010.

\section{Assortative Mating Correlation Coefficient}

The assortative mating correlation coefficient (ASMc) for each trait was calculated as the correlation between sire and dam GEBV from 211,709 genotyped family trios (sire, dam, and their offspring born after 2009), which can be defined as the measure of marker homozygosity. Extreme ASM may cause a reduction in within-family variance, possibly resulting in a reduction in additive genetic variance and then inflation in GEBV. When comparing 18 traits, ASMc can be a good indicator because it is different for each trait, whereas the homozygosity level is a single measurement for all 18 traits, which cannot explain different changes in heritability and biases in all 18 traits.

\section{Software}

Variance-covariance components for 18 linear type traits were estimated using a multiple trait model via the Gibbs sampler (GIBBS2F90), sampling 50,000

Table 1. Numbers of phenotypes, genotypes, and animals in 2014 and 2018 data sets

\begin{tabular}{|c|c|c|}
\hline \multirow[b]{2}{*}{ Numbers } & \multicolumn{2}{|c|}{ Data set } \\
\hline & 2014 & 2018 \\
\hline Phenotypes & $10,181,011$ & $10,946,264$ \\
\hline Cows with records & $6,634,328$ & $7,216,767$ \\
\hline Animals in pedigree & $10,679,591$ & $13,591,145$ \\
\hline Genotyped animals & 841,182 & $2,334,951$ \\
\hline $\begin{array}{l}\text { Males } \\
\text { with daughters }\end{array}$ & $\begin{array}{l}142,282 \\
22790(16,0 \%)\end{array}$ & 263,497 \\
\hline Females & 698,900 & $2,071,454$ \\
\hline with phenotypes & $127,402(18.2 \%)$ & $172,557(8.3 \%)$ \\
\hline
\end{tabular}

rounds and storing every 10th sample. After discarding 10,000 samples as burn-in, posterior means of $h^{2}$ and genetic correlations were calculated.

Given the large number of genotyped animals, the algorithm of proven and young (APY) by Misztal et al. (2014a) was used to obtain $\mathbf{G}^{-1}$. A total of 15,000 genotyped animals were randomly selected to be "core" and the remainder were treated as "noncore." The BLUP90IOD2 program (Tsuruta et al., 2001) was used to calculate $(\mathrm{G}) \mathrm{EBV}$ via the preconditioning conjugate gradient algorithm. The convergence criterion was based on the fraction of residuals in all solutions to the right-hand side in the MME (Tsuruta et al., 2001) and set to $10^{-12}$. The manual for blupf90 family of programs including GIBBS2F90 and BLUP90IOD2 is available at http://nce.ads.uga.edu/wiki/doku.php?id $\% 20=\% 20$ faq (Misztal et al., 2014b).

\section{RESULTS AND DISCUSSION}

\section{Genetic Parameter Estimates}

Table 2 shows heritability estimates $\widehat{\left(h^{2}\right)}$ and genetic correlations among 18 type traits for the last 16 years using 1999-2002 and 2015-2018 data sets (other 3 sets of parameter estimates for 2003-2006, 2007-2010, and 2011-2014 are not shown). In diagonals, left-to-right values present $\widehat{h^{2}}$ from 1999 to 2002 and 2015-2018 data sets, respectively. Genetic correlations from 1999 to 2002 are in the lower triangular region and those

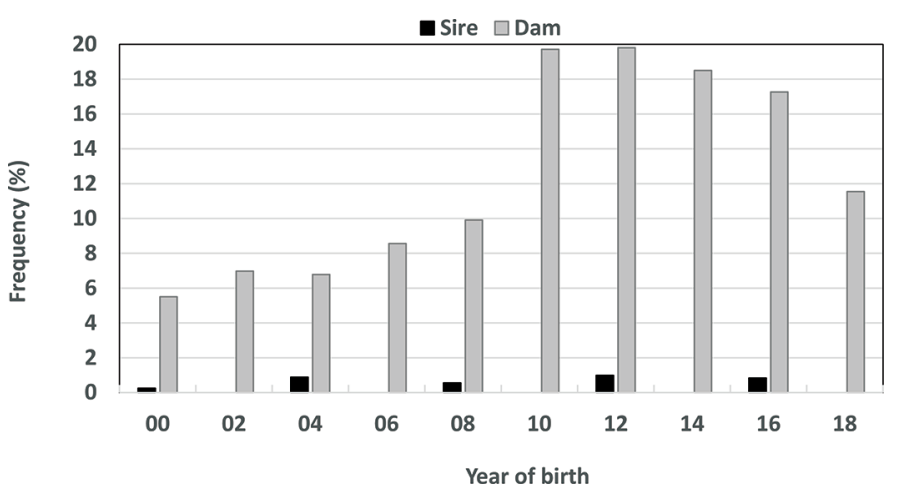

Figure 3. Distribution of unknown parents for genotyped animals born from 2000 to 2018 (00 to 18). 
Tsuruta et al.: SELECTION AND ASSORTATIVE MATING

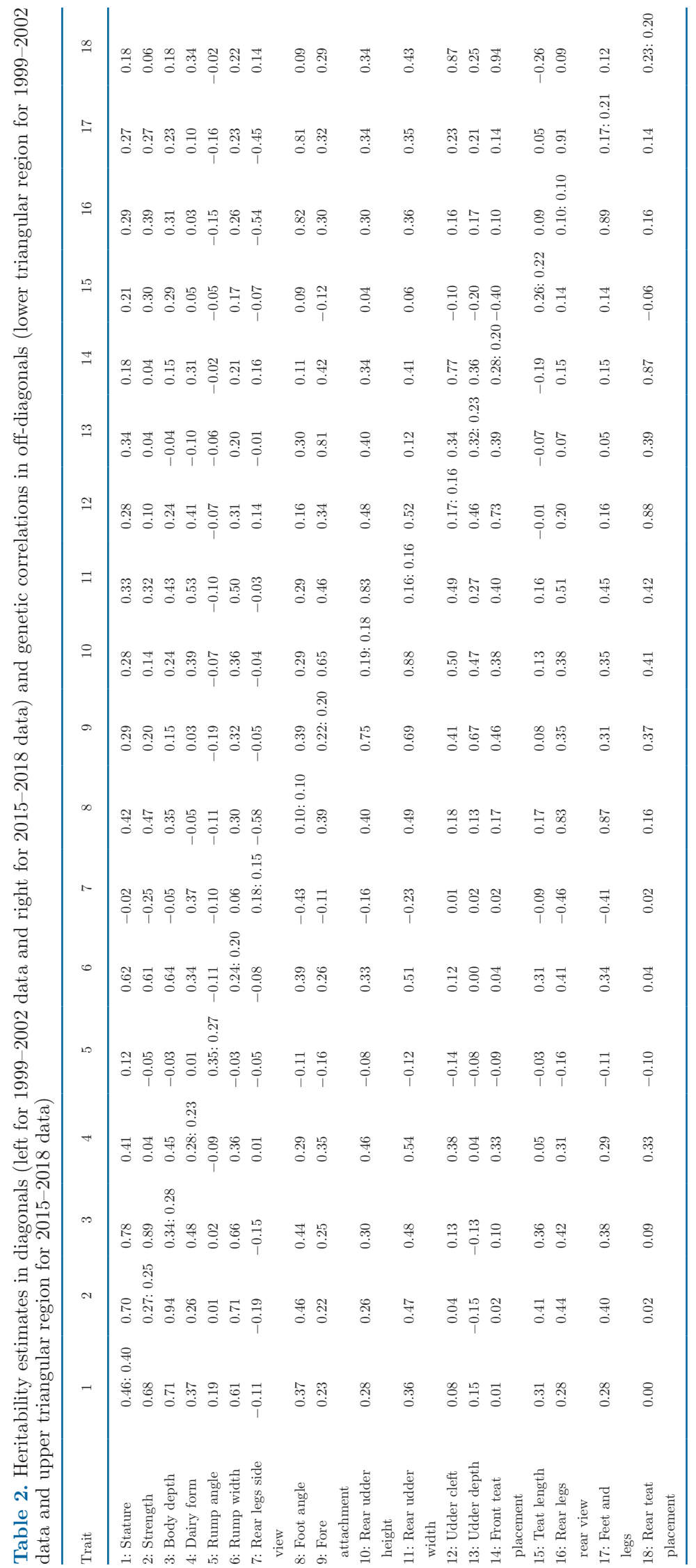



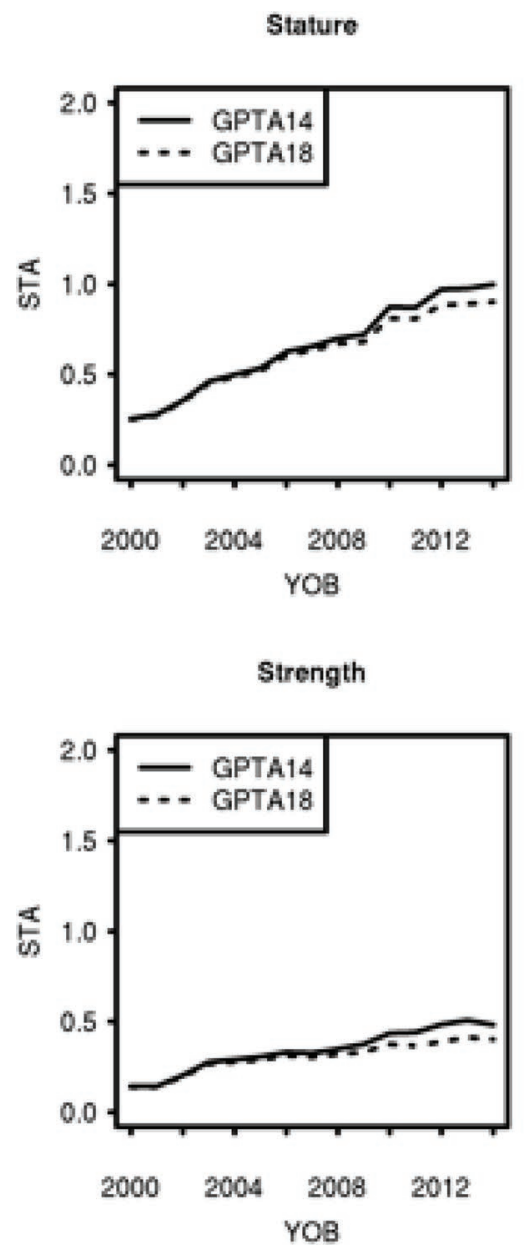

Body Depth

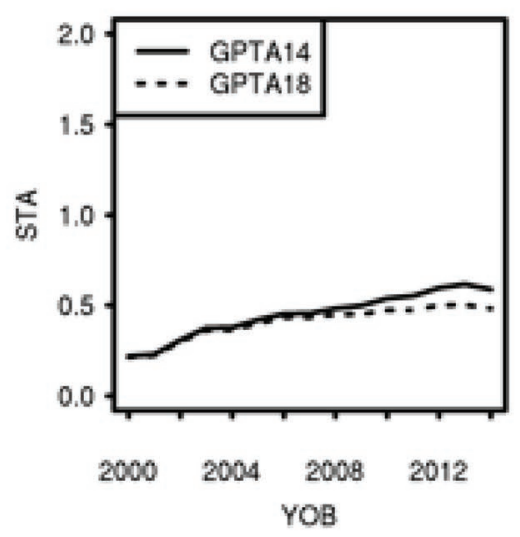

Rump Angle

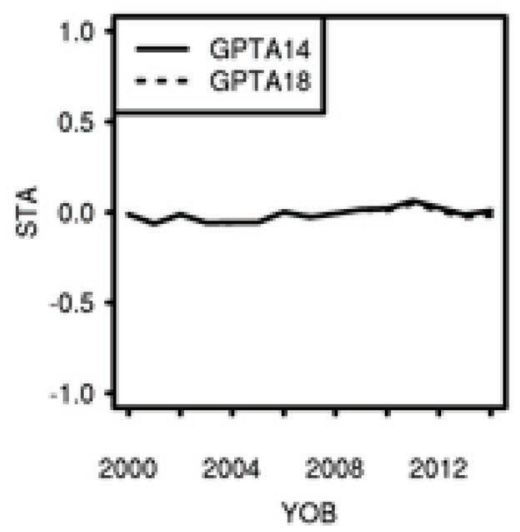

Rump Width

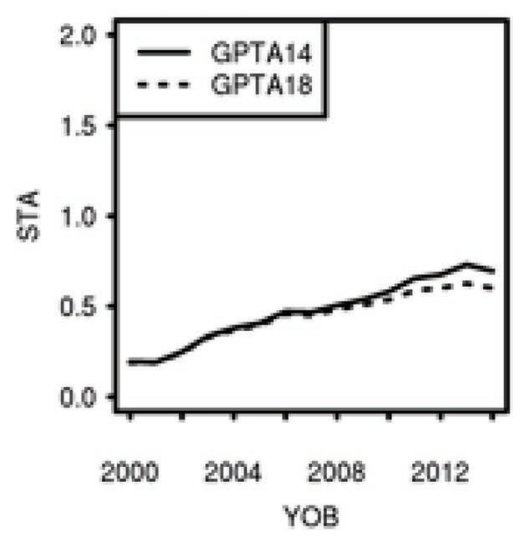

Dairy Form

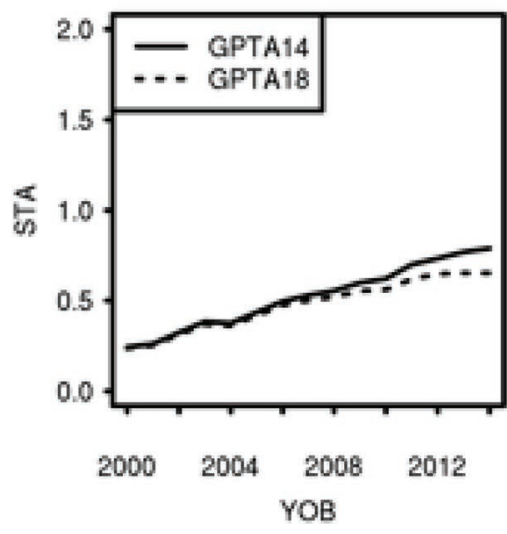

Figure 4. Genetic trends of body or structural traits and dairy form for Holstein bulls. STA = standardized PTA; GPTA14 = genomic PTA in 2014; GPTA18 = genomic PTA in 2018; YOB = year of birth.

from 2015 to 2018 are in the upper triangular region. The parameter estimates from 1999 to 2002 were chosen because they were similar to those currently used in the national genetic evaluation, which were estimated 14 yr ago (i.e., the correlation between the $2 \widehat{h^{2}}$ was $>0.99)$. In the last $16 \mathrm{yr}, \widehat{h^{2}}$ declined $3.3 \%$ on average, $\widehat{h^{2}}$ for 14 out of 18 traits declined, and $\Delta h^{2}$ ranged from -0.09 to 0.04 . Posterior SD of heritability for all traits were 0.01 . Therefore, the change in heritability estimates $>2$ or 3 SD (0.02 to 0.03 ) could be considered significant. In addition, all variance components also changed for $16 \mathrm{yr}$ : on average for 18 traits, changes were $-2.1,-0.5,7.1,0.1$, and $4.6 \%$ over the total variance in 1999-2002 for additive genetic, herd by sire, permanent environmental, residual, and total variance, respectively (not shown in Table 2). In this study, although the total variance and permanent environmental variance increased, the additive genetic variance declined. When the scale of phenotypes increases, the total variance also usually increases, as shown in this study. In that case, the change in additive genetic variance could increase as well, but it declined in this study. Considering the scale effect, a change in heritability could be a good measure to investigate how ASM affects the bias in GEBV. The $\Delta h^{2}$ will be discussed with genetic progress (GP) and bias in GEBV in a later section.

\section{Genetic Trend}

Genetic trends from 2014 and 2018 data sets for bulls are shown in Figures 4, 5, and 6, split by 3 body parts: body or structural traits including dairy form; feet and leg traits; and udder and teat traits. According to the pattern of the genetic trends in Figures 4, 5, 6, 7, 8, and 9 and based on the nature of the traits, the 18 linear type traits can be categorized into 3 groups: (1) high di- 
rectional selection, where the biological extreme is most desirable; (2) moderate selection; and (3) intermediate optimum selection. The first category involved body size (stature) and udder traits (rear udder height, rear udder width, and fore udder attachment). The third category involved rump angle, rear legs side view, and teat length. The rest of the linear type traits could be categorized in the second group. The first and second categories can be explained by positive ASM (but not always) and directional selection. The last category can be explained by negative ASM or disassortative mating. However, this categorization in genetic trend may not be straightforward because it can be affected by genetically correlated traits. When analyzing a large number of traits together, genetic factor and principal component analyses could be useful to focus on fewer traits.

For a fair comparison, the y-axis was scaled to the standardized PTA (STA). The genetic trend was cal- culated using only bulls with daughters having records in 2018 because Holstein bulls with no daughters cannot contribute anything to the population. Therefore, those bulls with no daughters should not be included in a genetic trend calculation even though they have GPTA calculated using only pedigrees and genotypes. Although young (genotyped) bulls may have daughters in the future, the inclusion of all (young) bulls in genetic trends results in underestimation when strong selection for that trait exists as presented in the simulation study by Tsuruta et al. (2019). In Figures 4, 5, and 6 , genetic trends for GPTA in 2014 (GPTA14 in the figures) included only bulls that had daughters in 2018, which means that they were selected. Therefore, they should be included to compare with genetic trends in 2018. That is, GPTA for young genotyped bulls born in 2014 were predicted with no daughters (GPTA14), and then GPTA for those bulls were predicted again when they had daughters with phenotypes in addition
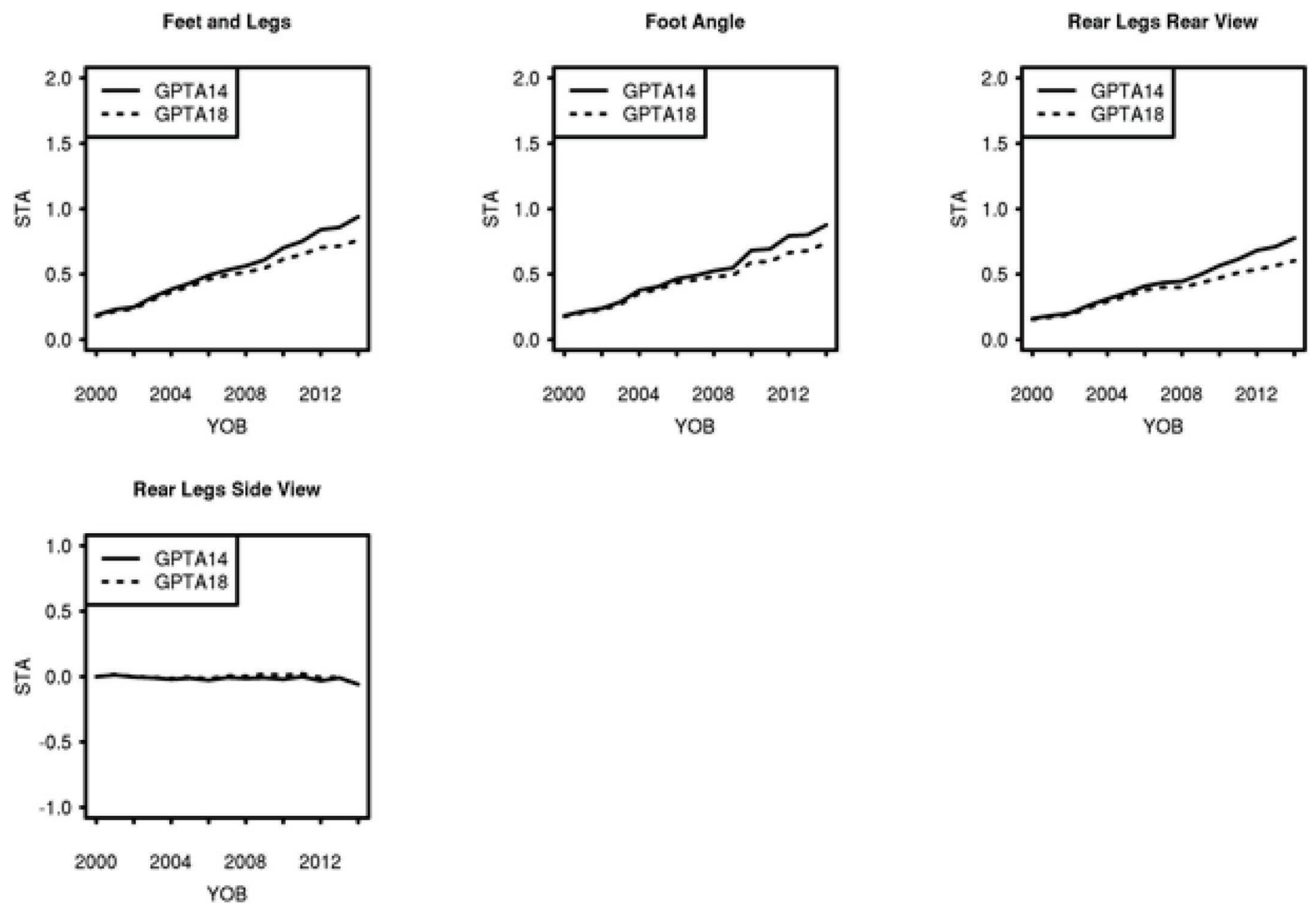

Figure 5. Genetic trends of feet and legs traits for Holstein bulls. STA = standardized PTA; GPTA14 = genomic PTA in 2014; GPTA18 = genomic PTA in 2018; YOB = year of birth. 


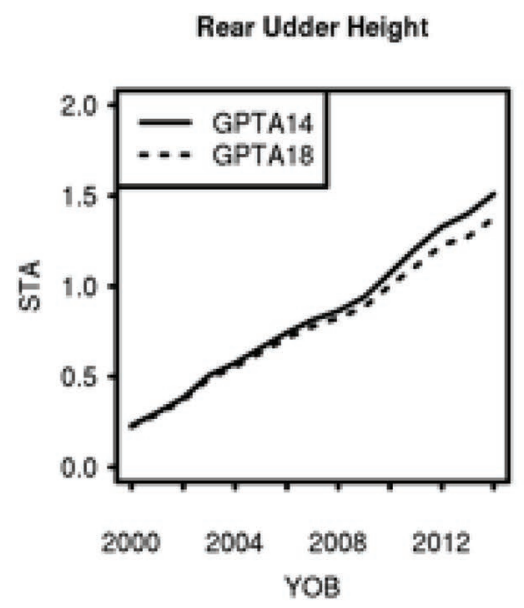

Udder Depth

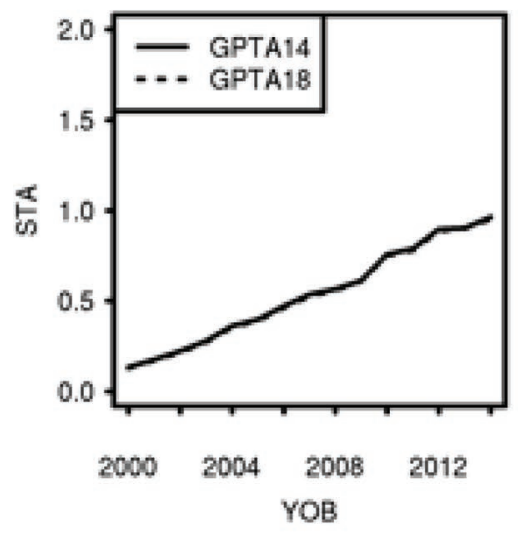

Rear Teat Placement

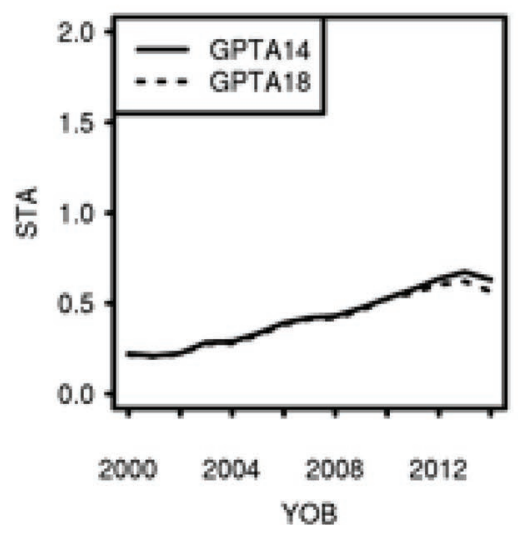

Rear Udder Width

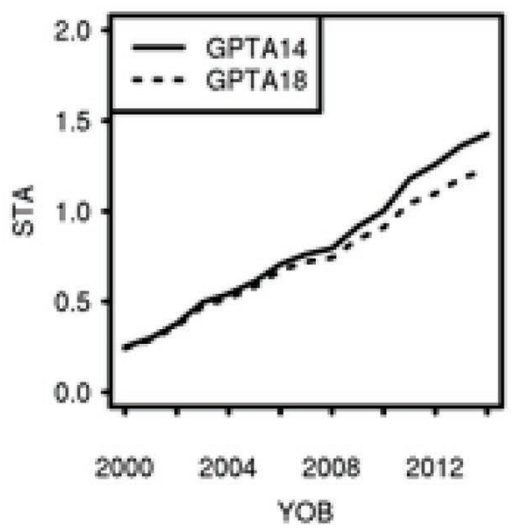

Udder Cleft

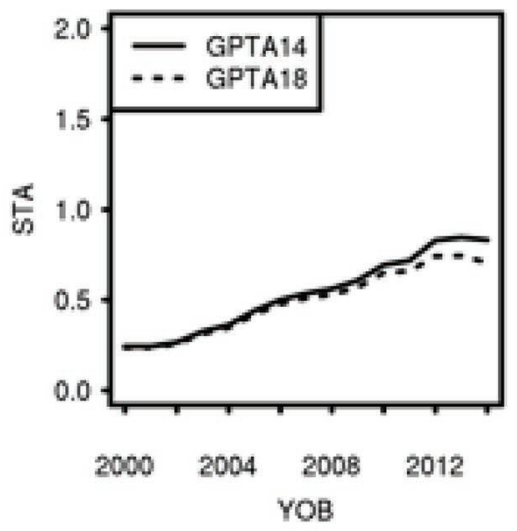

Teat Length

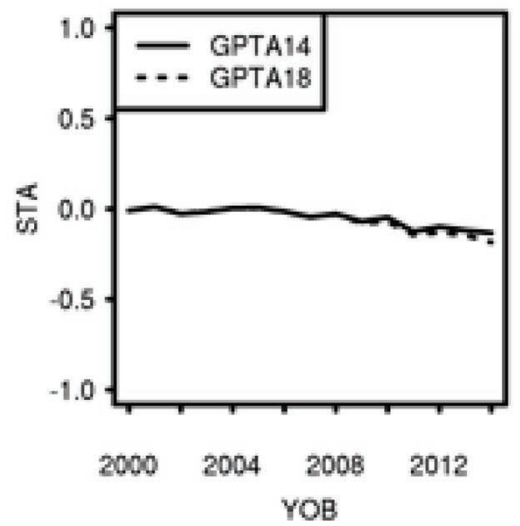

Fore Udder Attachment

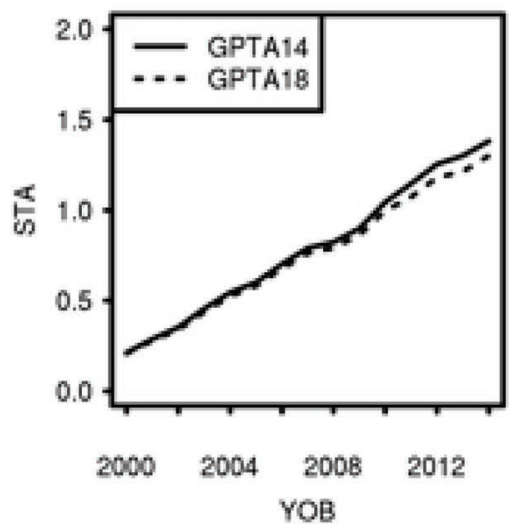

Front Teat Placement

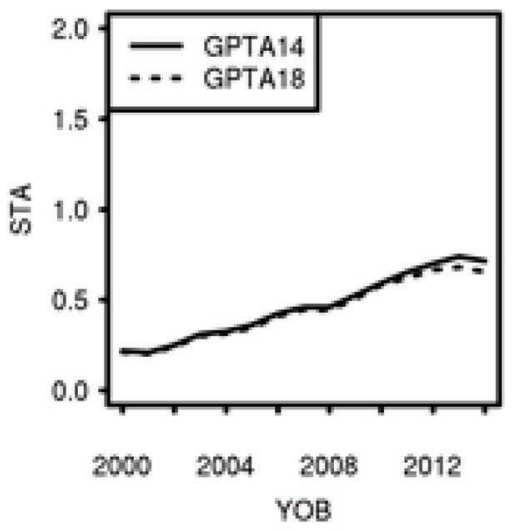

Figure 6. Genetic trends of udder traits for Holstein bulls. STA = standardized PTA; GPTA14 = genomic PTA in 2014; GPTA18 = genomic PTA in 2018; YOB = year of birth.

to more young animals with phenotypes or genotypes in 2018 (GPTA18 in the figures). Traits with more genetic gain tended to be overestimated in GPTA14. This overestimation will be investigated further in the next section. This result is also true for females that involve heifers. Figures 7, 8, and 9 show genetic trends for cows from 2014 and 2018 data sets. When young females (heifers) were evaluated using genotypes (and 
pedigrees) without phenotypes or using progeny with no phenotypes in 2014, they should not be included in genetic trend in 2014 (GPTA14). In Figures 7, 8, and 9, genetic trends for GPTA included only cows that had phenotypes in 2018. Although those young bulls with no daughters and young cows with no daughters or no phenotypes should not be included in the genetic trends for GPTA from 2014 data sets, those animals were included in these figures to compare with the trends in GPTA18. Preselection could cause the bias (inflation) in genetic trend (Masuda et al., 2018). However, the bias in genetic trend may be more affected by which animals were included in estimation of genetic trend as mentioned above and in Tsuruta et al. (2019).

\section{Reliability $\left(R^{2}\right)$, Bias $\left(b_{1}\right)$, and ASM}

Table 3 shows $\mathrm{R}^{2}$ and $\mathrm{b}_{1}$ from the regression model of DYD in 2018 on GEBV or GPA in 2014 for 1,401 young genotyped bulls with no daughters in 2014 and at least
50 daughters in 2018. When using old variance components $\widehat{\left(h^{2}\right)}$, the average $\mathrm{R}^{2}$ increased 26 percentage points from $32 \%$ for GPA to $58 \%$ for GEBV, and with new $\widehat{h^{2}}$, the increase in $\mathrm{R}^{2}$ was similar (i.e., 25 -percentage-point increase, from $32 \%$ for GPA to $57 \%$ for GEBV). Regression coefficients $b_{1}$, which indicate inflation $(<1.0)$ or deflation $(>1.0)$ of GPA and GEBV in 2014 evaluations, respectively, assuming DYD in 2018 are unbiased, were also similar when using old and new $\widehat{h^{2}}$. For all 18 type traits, $b_{1}$ for GEBV was 1.02 on average, ranging from 0.74 to 1.25 with old $\widehat{h^{2}}$ and from 0.75 to 1.20 with new $\widehat{h^{2}}$, demonstrating overall no significant inflation or deflation in GEBV but some bias depending on traits. Tsuruta et al. (2019) reported the average $\mathrm{b}_{1}=1.08$ with $570 \mathrm{~K}$ genotyped animals up to 2014. Those genotyped animals in 2014 were more strongly preselected and could create more bias in
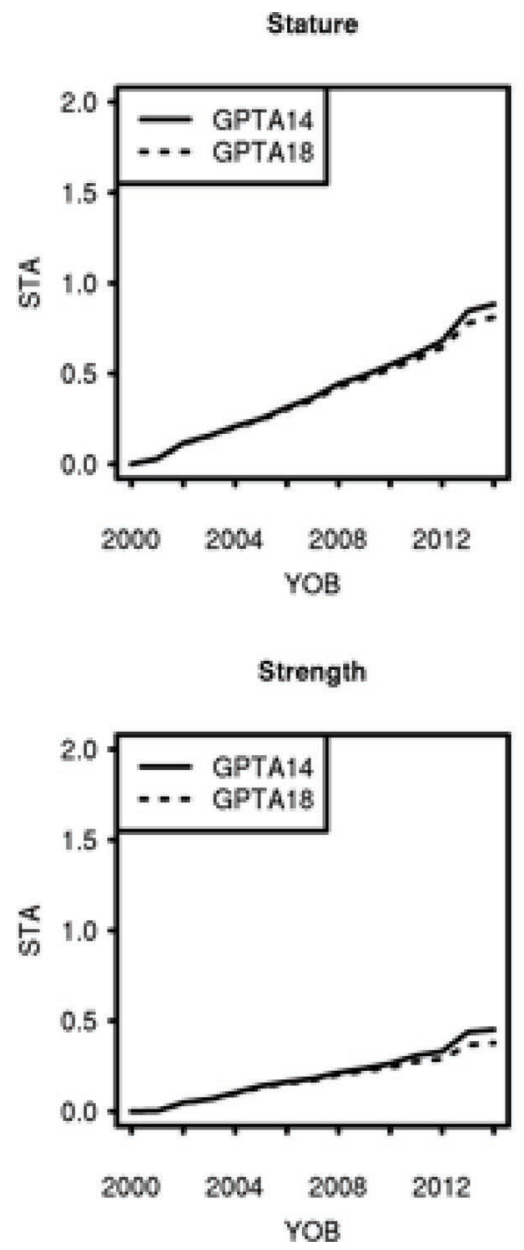

Body Depth

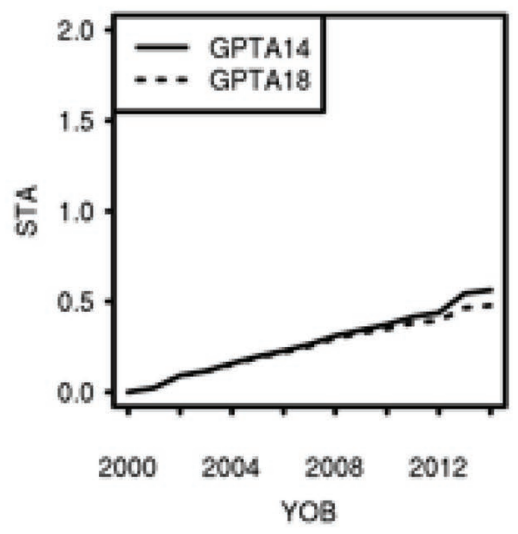

Rump Angle

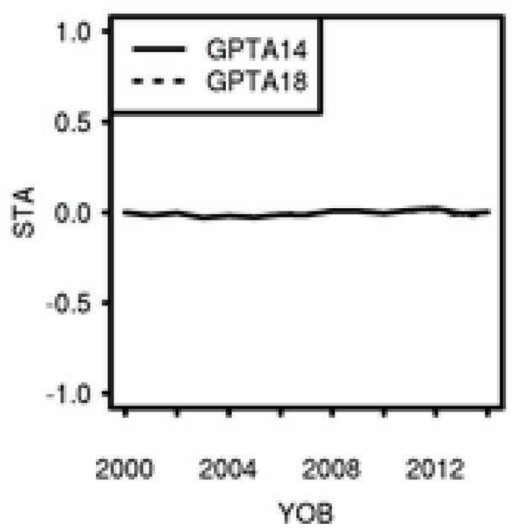

Rump Width

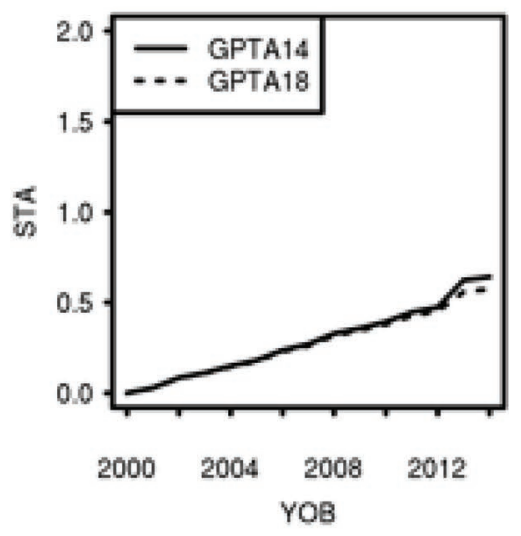

Dairy Form

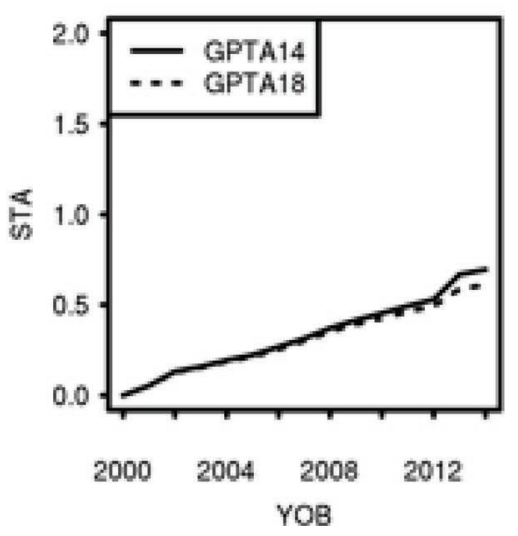

Figure 7. Genetic trends of body or structural traits and dairy form for Holstein cows. STA = standardized PTA; GPTA14 = genomic PTA in 2014; GPTA18 = genomic PTA in 2018; YOB = year of birth. 

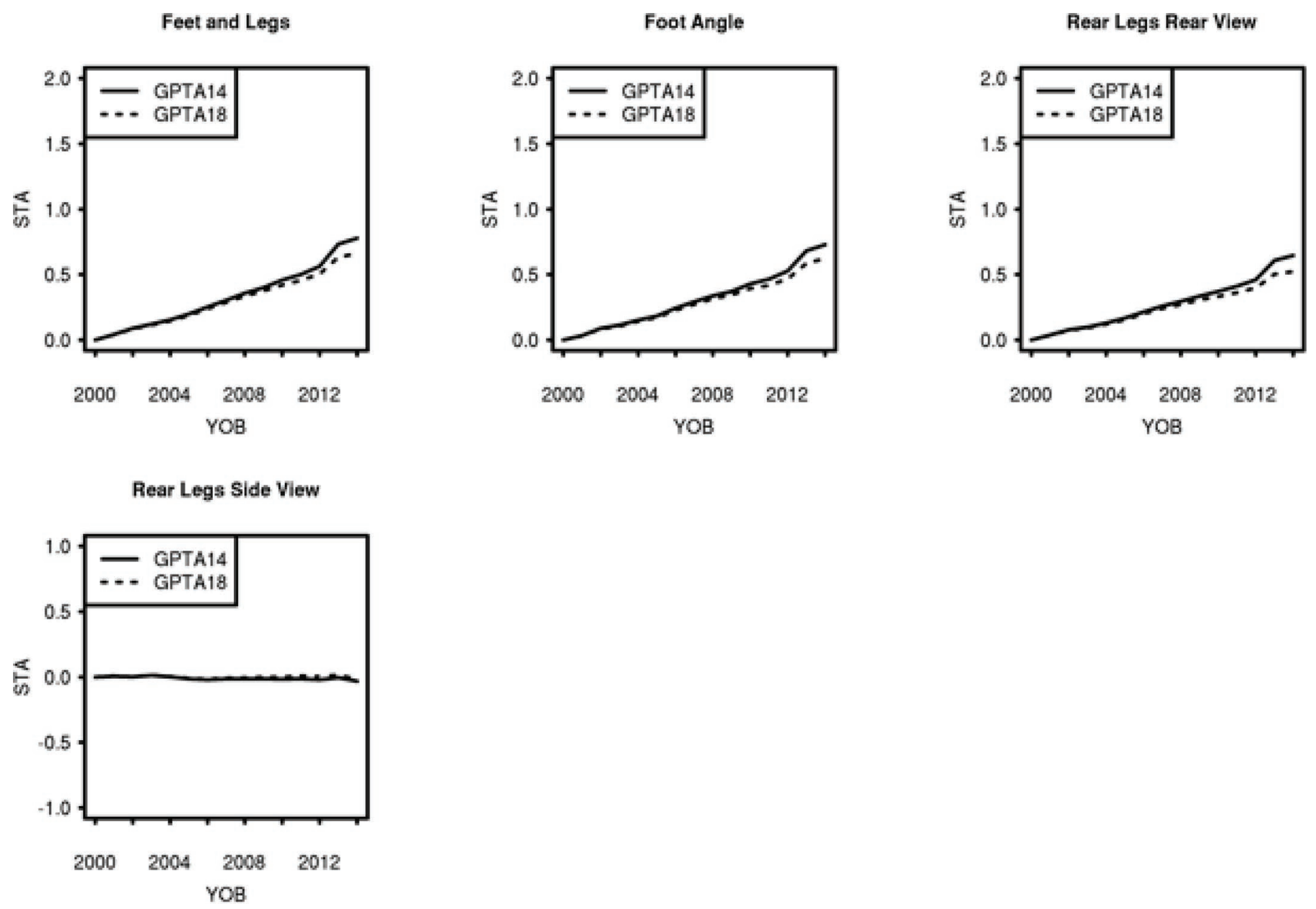

Figure 8. Genetic trend of feet and legs traits for Holstein cows. STA = standardized PTA; GPTA14 = genomic PTA in 2014; GPTA18 = genomic PTA in 2018; YOB = year of birth.

GEBV. The result from this study indicates that the inconsistency between $\mathbf{G}^{-1}$ and $\mathbf{A}^{-1}$ was improved by accumulating a large number of genotypes.

As shown in Table 3 , the results with new $\widehat{h^{2}}$ were similar to those from old $\widehat{h^{2}}$, suggesting that inflation and deflation may not be directly due to $\Delta h^{2}$ in $16 \mathrm{yr}$. Except for "feet and legs" with an increase of 0.04 in $\Delta h^{2}$, the $h^{2}$ for most of the traits declined in the last 16 yr. Using new $\widehat{h^{2}}$, the GEBV for "feet and legs" was still inflated $\left(b_{1}=0.75\right)$, and GEBV for "rear teat placement" was deflated $\left(b_{1}=1.20\right)$. This result does not make sense because when $h^{2}$ is underestimated, GEBV should be underpredicted. Likewise, when $h^{2}$ is overestimated, GEBV should be overpredicted. For GPA in 2014, $b_{1}$ was 0.96 on average, which was largely inflated $\left(b_{1}=0.76\right)$ in 2010 (Tsuruta et al., 2019). One reason that GPA for those young genotyped bulls was inflated in the previous study was the use of parent averages from EBV instead of GEBV, whereas GPA in the present study was calculated from GEBV in 2014, implying that genetic bases for parent averages (EBV) and GPA (GEBV) were different. The base of GPA, which included genotypes, could be different from the base of parent averages without genotypes.

The ASMc varied for different traits from -0.07 to 0.30 (Table 3). Traits in which an intermediate optimum is desirable, such as teat length, rump angle, and rear legs side view, had an average ASMc of -0.03 , indicating that breeders tend to make a corrective mating; that is, negative ASM. In contrast, a trait in which a high conformation score is associated with a desirable linear change toward a biological extreme showed positive ASM. The highest ASMc were for rear udder height $(0.30)$ and rear udder width $(0.26)$. These 2 traits were under strong selection intensity as they are positively correlated with a greater capacity for higher milk yield.

Gowane et al. (2019) reported a simulation study on the predictive ability of ssGBLUP with data mimicking 
the effects of selection and positive ASM. With simulated data including inbreeding in $\mathbf{A}^{-1}$ and $\mathbf{A}_{22}^{-1}$, genomic predictions were unbiased, and their reliabilities were highest with the scenario of no selection and ran- dom mating (Table 4). Selection with random mating without accounting for inbreeding in the $\mathbf{A}$ matrix resulted in a small amount of bias $\left(b_{1}\right)$ and a decrease in reliability. When selection and positive ASM between

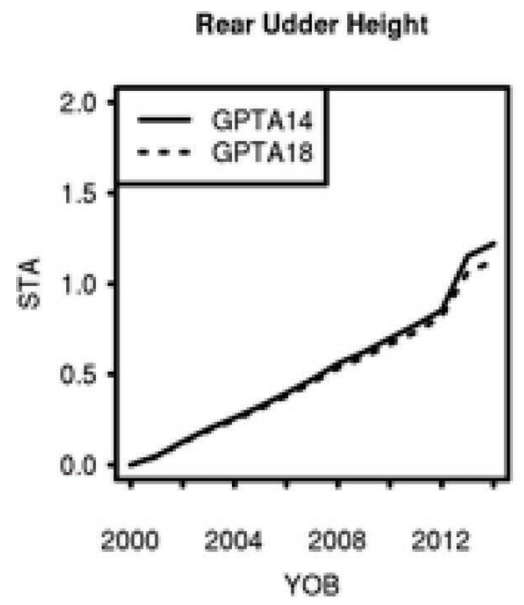

Udder Depth

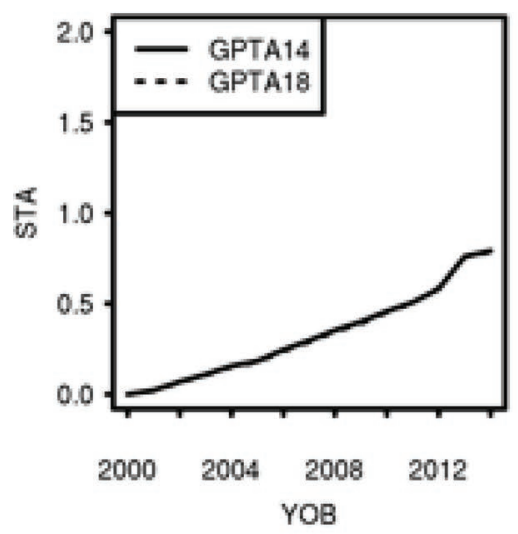

Rear Teat Placement

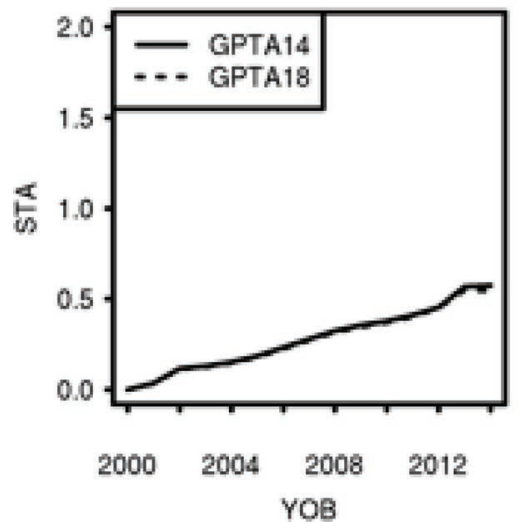

Rear Udder Width

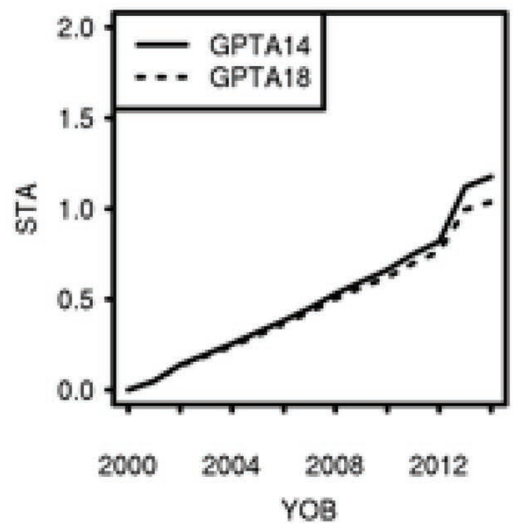

Udder Cleft

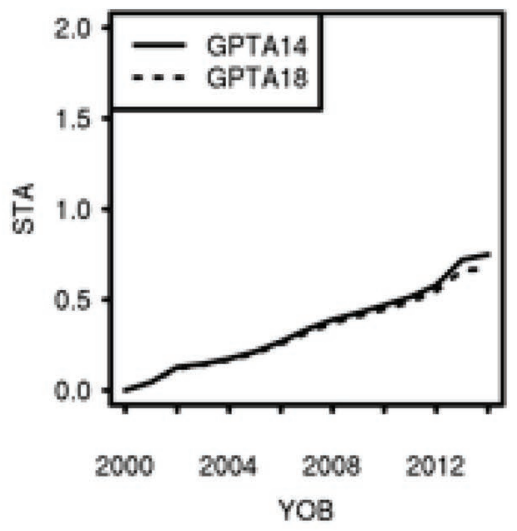

Teat Length

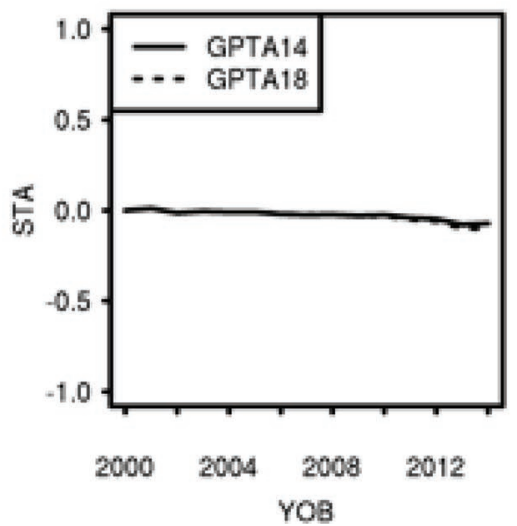

Fore Udder Attachment

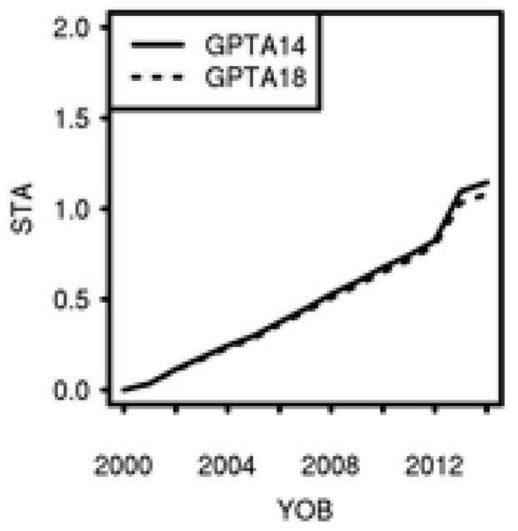

Front Teat Placement

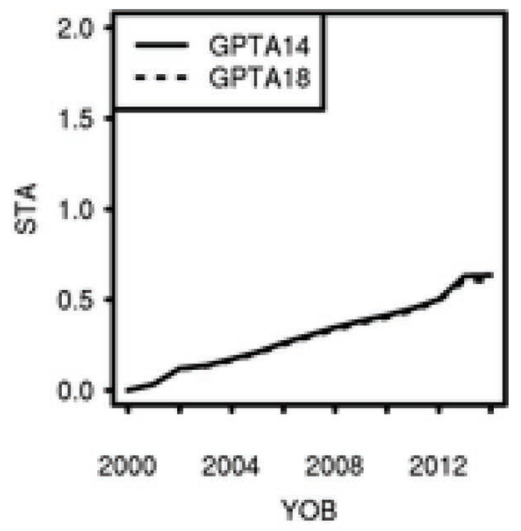

Figure 9. Genetic trends of udder traits for Holstein cows. STA = standardized PTA; GPTA14 = genomic PTA in 2014; GPTA18 = genomic PTA in 2018; YOB = year of birth. 
Table 3. Coefficient of determinant $\left(\mathrm{R}^{2}\right)$ and regression coefficient $\left(\mathrm{b}_{1}\right)$ of DYD ${ }^{1}=\mathrm{b}_{0}+\mathrm{b}_{1} \times \mathrm{GEBV}^{2}$ or GPA $\mathrm{G}^{3}$ for 1,401 young genotyped bulls with no daughters in 2014 and at least 50 daughters in 2018, genetic progress (GP), changes in heritability $\left(\Delta h^{2}\right)$, and correlations of GEBV for mates (i.e., assortative mating correlations ${ }^{4}$ )

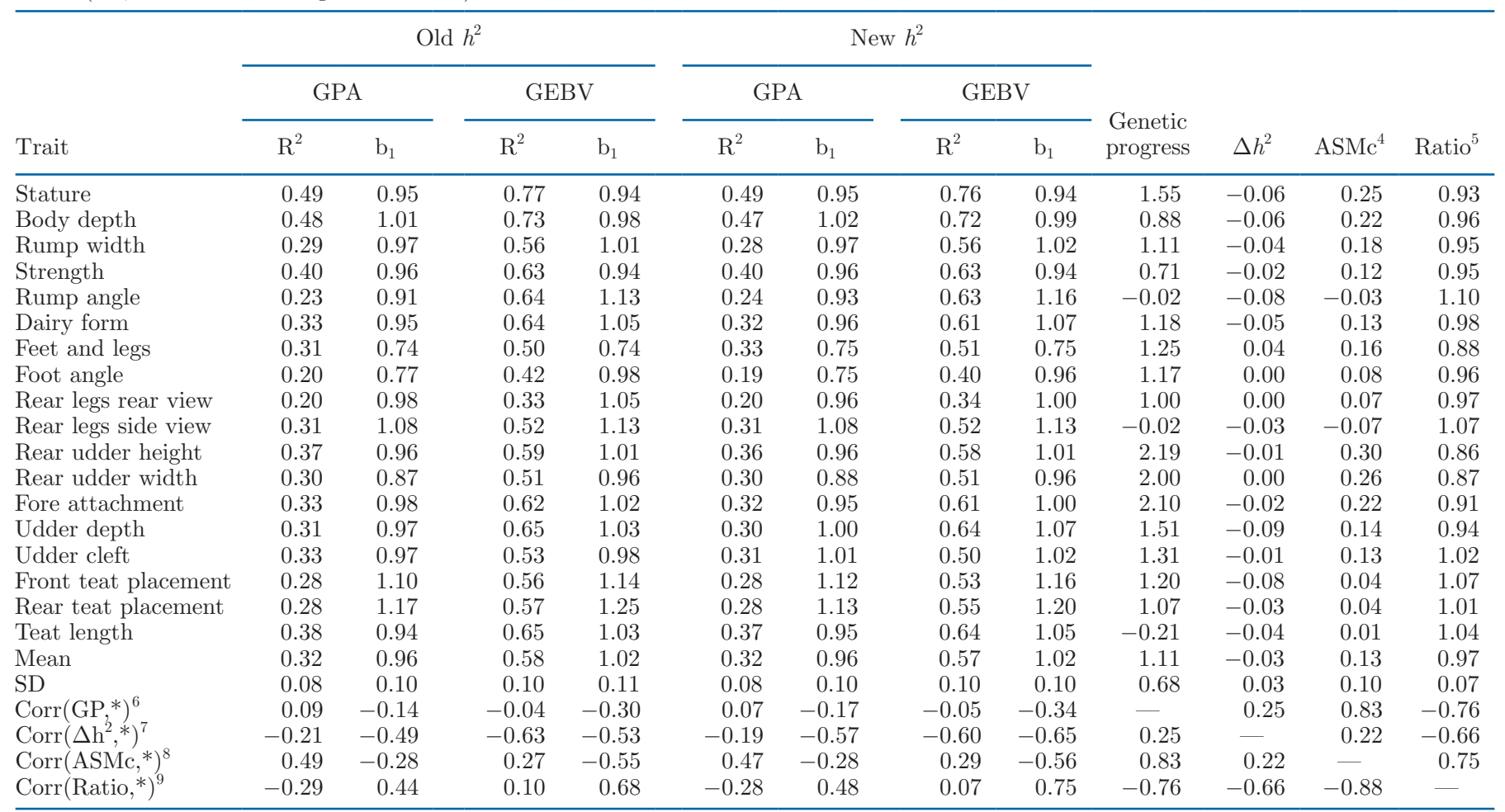

${ }^{1}$ Daughter yield deviation in 2018 .

${ }^{2}$ Genomic EBV in 2014.

${ }^{3}$ Genomic parent average in 2014 .

${ }^{4}$ Assortative mating correlation (ASMc) calculated between GEBV for parents of genotyped bulls from 2009 to 2014.

${ }^{5}$ Ratio $\left(1-\frac{1}{2} \mathrm{ASMc}\right) /\left(1+\Delta h^{2}\right)$.

${ }^{6}$ Correlation with standardized GP calculated by (genetic base in 2014 - genetic base in 2000)/additive genetic SD. Asterisk indicates each column.

${ }^{7}$ Correlation with $\Delta \mathrm{h}^{2}$ calculated as $\left(h^{2}\right.$ in $2018-h^{2}$ in 2004). Asterisk indicates each column.

${ }^{8}$ Correlation with ASMc. Asterisk indicates each column.

${ }^{9}$ Correlation with ratio. Asterisk indicates each column.

parents took place, there was a large increase in bias (i.e., decrease in $b_{1}$ ) and a further reduction in reliability. In this study, positive ASM caused a lowering of $\mathrm{b}_{1}$ with a correlation of -0.55 : -0.56 between ASMc and $\mathrm{b}_{1}$ (old $h^{2}$ : new $h^{2}$, respectively; the same notation applies hereafter). Conversely, the $b_{1}$ values for traits

Table 4. Estimated bias $\left(\mathrm{b}_{1}\right)$ and reliability $\left(\mathrm{R}^{2}\right)$ in simulated data with selection and positive assortative mating (adapted from Tables 1 and 3 in Gowane et al., 2019)

\begin{tabular}{|c|c|c|c|c|c|c|}
\hline \multirow[b]{3}{*}{ Simulation design } & \multicolumn{4}{|c|}{ Simulation ${ }^{1}$} & \multirow{2}{*}{\multicolumn{2}{|c|}{$\begin{array}{c}\text { Current study } \\
\text { Inbreeding }\end{array}$}} \\
\hline & \multicolumn{2}{|c|}{ No inbreeding } & \multicolumn{2}{|c|}{ Inbreeding } & & \\
\hline & $\mathrm{b}_{1}$ & $\mathrm{R}^{2}$ & $\mathrm{~b}_{1}$ & $\mathrm{R}^{2}$ & $\mathrm{~b}_{1}$ & $\mathrm{R}^{2}$ \\
\hline No selection; random mating & 0.99 & 0.68 & 1.01 & 0.68 & - & - \\
\hline Selection; random mating & 0.94 & 0.60 & 1.00 & 0.60 & 1.10 & 0.53 \\
\hline Selection; assortative mating & 0.69 & 0.63 & 0.97 & 0.68 & 0.90 & 0.56 \\
\hline
\end{tabular}


with low or negative ASM were higher than for the traits undergoing high genetic gain and the accompanying positive ASM. When inbreeding is known precisely and accounted for in $\mathbf{A}^{-1}$ and $\mathbf{A}_{22}^{-1}$, bias was essentially eliminated, indicating that a source of the lower $b_{1}$ is an increase in both the homozygosity of individuals and the covariance between parents (ASM). In the current study, inbreeding and UPG for missing parents of animals were included in the model. However, clear differences in $b_{1}$ values still existed between traits with positive ASM and traits with low to negative ASM mating, indicating that we have not yet fully accounted for the covariance between sire and offspring by different ASM practices.

\section{$G P, \Delta h^{2}$, and $A S M$}

Table 3 also includes GP and $\Delta h^{2}$. Traits making higher GP showed a decline in $h^{2}$ and higher ASMc. Higher levels of positive ASM resulted in a greater reduction in the covariance between early and later genomic predictions and in lower $b_{1}$ values (inflation $<1.0)$. Traits with an intermediate optimum also showed a decline in $h^{2}$; however, the low to negative ASM resulted in larger covariances between early and later genomic predictions and in higher $b_{1}$ values (deflation $>1.0)$. The negative correlation of -0.30 : -0.34 between $b_{1}$ and GP, which was standardized by the old additive genetic SD, implies that traits with more genetic gain were likely more inflated in GEBV. In other words, traits undergoing less genetic gain were likely more deflated. This result suggests that strong selection could cause inflation in GEBV. Additionally, it is interesting to show a positive but low correlation of 0.25 between $\Delta h^{2}$ and GP, suggesting that shrinking additive genetic variances could be due to some other factors in addition to the strong selection intensity. In general, traits exhibiting higher GP were strongly associated with a higher estimate of positive ASM, and the correlation between ASMc and GP was 0.83. This may be explained by the actions of the breeders or as a function of selection. Genomic selection increases the frequency of desirable SNP. Over time, selected animals will carry more of the same desirable SNP, leading to greater homozygosity and linkage disequilibrium among the markers, along with a reduction in the genetic variation within a family. Exploitation of desirable Mendelian sampling effects is an important component of the success of genomic selection because it uses realized relationships rather than expected pedigree relationships. With genomic selection, random mating should not be assumed, because traits making large genetic gains will most likely exhibit a positive correlation of GEBV between mates.

The conformation traits in Table 3 were ranked by the amount of ASM within 3 groups (body or structural traits, feet and legs, and udder and teat traits) and dairy form in the same order as in Figures 4 through 9. The effect of selection upon $h^{2}$ can be complex. Although selection decreases the additive genetic variance, it creates an increase in the covariance between mates. Positive ASM leads to an increase in the additive genetic variance and $h^{2}$ (Crow and Kimura, 1970). Among the traits in this study, a low but positive correlation of 0.22 was observed between $\Delta h^{2}$ and ASMc; that is, higher ASM resulted in a smaller decrease in $\Delta h^{2}$. As expected, traits with higher $h^{2}$ in the initial years (2000-2004) showed larger decreases in $h^{2}$ (i.e., the correlation between $h^{2}$ in $2000-2004$ and $\Delta h^{2}$ was $-0.77)$ in the later years (2015-2018).

An important step in the successful application of genomic selection for dairy cattle is the validation of the model used in a study. The formula from Falconer and Mackay (1996),

$$
h_{1}^{2}=h_{0}^{2}\left(\frac{1+\frac{1}{2} A S M c}{1+\frac{1}{2} A S M c \times h^{2}}\right),
$$

shows that ASMc is responsible for the change in heritability, where $h_{0}^{2}$ is the base heritability of random mating and $h_{1}^{2}$ is the heritability after one generation of ASM. With reference to this formula, we used the ratio

$$
\left[\left(1-\frac{1}{2} A S M c\right) /\left(1+\Delta h^{2}\right)\right]
$$

which could explain how ASMc in the numerator and the Bulmer effect (Bulmer, 1971) in the denominator affect $b_{1}$ in GEBV. The constant $\frac{1}{2}$ is from one parent (one allele) to describe a change in the covariance between sire and offspring. The ratio could also explain the reduction due to increasing the fraction of assortative mating (homozygosity) in the heritability change $\left(\Delta h^{2}\right)$. That is, more ASM creates more inflation in GEBV. As described before, a forward prediction procedure was used where the bias in GEBV was assessed from the regression coefficient $b_{1}$ of a later genomic prediction (with progeny) on an earlier genomic prediction (without progeny). The addition of progeny information increases the proportion of within-family variance in GEBV over GPA (Clark et al., 2013). Thus, 
ASM can be one of the causes for $b_{1}$ to deviate from 1.0 (inflation when $\mathrm{b}_{1}<1.0$ ). Both the numerator (DYD) and denominator (GEBV or GPA) of $b_{1}$ can be affected by selection. The numerator of the $b_{1}$ value in the regression model is the covariance between the early GPA and the GEBV (with progeny). This covariance is reduced by $1-\frac{1}{2} A S M c$ due to an increase in homozygosity of the progeny; that is, a reduction in within-family variance. The denominator is the variance of the early GPA. This is reduced by $1+\Delta h^{2}$ due to selection and the Bulmer effect; that is, a reduction in between-family variance. A change in the within-family genetic variance $1-\frac{1}{2} A S M c$ is reflected in the covariance between early and later genomic predictions, whereas a reduction in between-family variance $1+\Delta h^{2}$ alters the denominator by reducing the estimated genetic variance.

Information on GP, ASM, $\Delta h^{2}$, and the ratio of $\left[\left(1-\frac{1}{2} A S M c\right) /\left(1+\Delta h^{2}\right)\right]$ provides valuable information on differences in $b_{1}$ values (bias in GEBV) for different traits in Table 3. The correlations of these variables (GP, ASM, $\Delta h^{2}$, and the ratio) with $\mathrm{b}_{1}$ for GEBV with new $h^{2}$ were $-0.34,-0.56,-0.65$, and 0.73 , respectively. Traits with higher genetic gain, positive ASM, and a greater decrease in heritability resulted in a decrease in their $b_{1}$ values; that is, the early predictions were too high. However, the ratio $\left[\left(1-\frac{1}{2} A S M c\right) /\left(1+\Delta h^{2}\right)\right]$ had the highest correlation with $b_{1}$. Simultaneously accounting for a change in the sire-offspring covariance $1-\frac{1}{2} A S M c$ and a reduction in the genetic variance due to the Bulmer effect $1+\Delta h^{2}$ was necessary to describe the bias involved in our early predictions. This measure of change in genetic (co)variances is approximate; however, the ratio was able to track $b_{1}$ values well: the correlations (0.68: 0.75$)$ between $b_{1}$ and the ratio were higher than those (0.55: 0.56$)$ between $b_{1}$ and $1-\frac{1}{2} A S M c$, implying that changes in genetic variances could explain the bias in genomic predictions. Within each body group, the correlations between $b_{1}$ and the ratio were high: 0.92: 0.92, 0.91: 0.96 , and 0.59: 0.77 for body or structural traits, feet and legs traits, and udder and teat traits, respectively (here, statistically significant when correlation is greater than $0.8,0.9$, and 0.7, respectively, in each body group).

The reliability of our model $\left(\mathrm{R}^{2}\right)$ was also affected by $\Delta h^{2}$. A greater decrease in heritability $\left(\Delta h^{2}\right)$ was correlated (-0.63: -0.60$)$ with higher $\mathrm{R}^{2}$. Similarly, higher ASMc was positively correlated (0.27: 0.29) with higher $\mathrm{R}^{2}$. Knowing why early predictions of genetic merit result in over- or underprediction of later evaluations is valuable when judging the performance of a model and for identifying further model improvements.

Large genetic gains with high directional selection intensity were made in stature and udder traits, and the bias in GEBV for these traits was small, suggesting that strong selection was not always a major cause of bias. These udder traits may have been directionally selected, and stature may have been selected with strong intensity and positive ASM. Rump angle, rear legs side view, and teat length, which could have the negative ASM or disassortative mating, were deflated in GEBV and had slightly negative GP.

The negative correlation of $-0.53:-0.65$ between $b_{1}$ in GEBV and the $\Delta h^{2}$ for the last 16 yr in Table 3 indicates that traits with decreasing $h^{2}$ (additive genetic variance) were likely to have more deflated $\left(b_{1}>1.0\right)$ GEBV. Feet and legs score was an exception, which had increased $h^{2}$ and the most inflated GEBV. The linear type data collection started in 1983, but 3 linear traits started later: rear legs rear view in 1989, feet and legs in 1993, and rear teat placement in 2001. The results in $b_{1}$ for these newly evaluated traits may be less stable compared with other traits.

\section{CONCLUSIONS}

Considering inbreeding in all relationships and assigning estimable unknown parent groups in the ssGBLUP, a large-scale genomic evaluation is feasible without significant biases for 18 linear type traits in more than 2.3 million genotyped US Holsteins. The bias in genomic predictions due to preselection is insignificant when the number of genotyped animals increases. Observed inflation or deflation in genomic predictions for individual traits can be partially explained by selection intensity, changes in heritability, and different mating practices. Strong selection is not fully responsible for bias in genomic predictions for genotyped animals in future generations. However, bias in genomic predictions can be explained by positive assortative mating, which may affect the within-family genetic variance, causing a reduction in the covariance between sire and offspring. The relationship between selection intensity and positive assortative mating could be responsible for bias in genomic predictions; that is, more positive assortative mating leads to more inflation.

\section{ACKNOWLEDGMENTS}

This study was partially funded by the Holstein Association USA Inc. (Brattleboro, VT). The authors thank the Council on Dairy Cattle Breeding (CDCB; 
Bowie, MD) for providing genomic data. The authors confirm that they have no conflicts of interest.

\section{REFERENCES}

Aguilar, I., and I. Misztal. 2008. Recursive algorithm for inbreeding coefficients assuming non-zero inbreeding of unknown parents. J. Dairy Sci. 91:1669-1672. https://doi.org/10.3168/jds.2007-0575.

Aguilar, I., I. Misztal, D. L. Johnson, A. Legarra, S. Tsuruta, and T. J. Lawlor. 2010. Hot topic: A unified approach to utilize phenotypic, full pedigree and genomic information for genetic evaluation of Holstein final score. J. Dairy Sci. 93:743-752. https://doi.org/10 $.3168 /$ jds.2009-2730.

Bonk, S., M. Reichelt, F. Teuscher, D. Segelke, and N. Reinsch. 2016. Mendelian sampling covariability of marker effects and genetic values. Genet. Sel. Evol. 48:36-46. https://doi.org/10.1186/s12711 $-016-0214-0$.

Bradford, H. L., Y. Masuda, P. M. VanRaden, A. Legarra, and I. Misztal. 2019. Modeling missing pedigree in single-step genomic BLUP. J. Dairy Sci. 102:2336-2346. https://doi.org/10.3168/jds .2018-15434.

Bulmer, M. G. 1971. The effect of selection on genetic variability. Am. Nat. 105:201-211. https://doi.org/10.1086/282718.

Clark, S. A., B. P. Kinghorn, J. M. Hickey, and J. H. J. van der Werf. 2013. The effect of genomic information on optimal contribution selection in livestock breeding programs. Genet. Sel. Evol. 45:44. https://doi.org/10.1186/1297-9686-45-44.

Crow, J. F., and M. Kimura. 1970. An Introduction to Population Genetics Theory. Chapter 4. Harper and Row, New York, NY.

Falconer, D. S., and T. F. C. Mackay. 1996, Introduction to Quantitative Genetics. 4th ed. Chapter 15. Pearson Education/Longman, Essex, UK.

Gowane, G. R., S. H. Lee, S. Clark, N. Moghaddar, H. A. Al-Mamun, and J. H. J. van der Werf. 2019. Effect of selection and selective genotyping for creation of reference on bias and accuracy of genomic prediction. J. Anim. Breed. Genet. 136:390-407. https://doi .org/10.1111/jbg.12420.

Legarra, A., I. Aguilar, and I. Misztal. 2009. A relationship matrix including full pedigree and genomic information. J. Dairy Sci. 92:4656-4663. https://doi.org/10.3168/jds.2009-2061.

Legarra, A., O. F. Christensen, Z. G. Vitezica, I. Aguilar, and I. Misztal. 2015. Ancestral relationships using metafounders: Finite ancestral populations and across population relationships. Genetics 200:455-468. https://doi.org/10.1534/genetics.115.177014.

Masuda, Y., P. M. VanRaden, I. Misztal, and T. J. Lawlor. 2018. Differing genetic trend estimates from traditional and genomic evaluations of genotyped animals as evidence of preselection bias in US Holsteins. J. Dairy Sci. 101:5194-5206. https://doi.org/10.3168/ jds.2017-13310.

Misztal, I., A. Legarra, and I. Aguilar. 2014a. Using recursion to compute the inverse of the genomic relationship matrix. J. Dairy Sci. 97:3943-3952. https://doi.org/10.3168/jds.2013-7752.

Misztal, I., S. Tsuruta, D. Lourenco, Y. Masuda, I. Aguilar, A. Legarra, and Z. Vitezica. 2014b. Manual for blupf90 family of pro- grams. Accessed on July 10, 2020. http://nce.ads.uga.edu/wiki/ doku.php?id=faq.

Misztal, I., Z. G. Vitezica, A. Legarra, I. Aguilar, and A. A. Swan. 2013. Unknown-parent groups in single-step genomic evaluation. J. Anim. Breed. Genet. 130:252-258. https://doi.org/10.1111/jbg .12025 .

Mrode, R. A., and G. J. T. Swanson. 2004. Calculating cow and daughter yield deviations and partitioning of genetic evaluations under a random regression model. Livest. Prod. Sci. 86:253-260. https://doi.org/10.1016/j.livprodsci.2003.09.001.

Patry, C., and V. Ducrocq. 2011. Evidence of biases in genetic evaluations due to genomic preselection in dairy cattle. J. Dairy Sci. 94:1011-1020. https://doi.org/10.3168/jds.2010-3804.

Tsuruta, S., D. Lourenco, Y. Masuda, I. Misztal, and T. Lawlor. 2019 Controlling bias in genomic breeding values for young genotyped bulls. J. Dairy Sci. 102:9956-9970. https://doi.org/10.3168/jds .2019-16789.

Tsuruta, S., I. Misztal, L. Klei, and T. J. Lawlor. 2002. Analysis of age-specific predicted transmitting abilities for final scores in Holsteins with a random regression model. J. Dairy Sci. 85:1324-1330. https://doi.org/10.3168/jds.S0022-0302(02)74197-0.

Tsuruta, S., I. Misztal, D. A. L. Lourenco, and T. J. Lawlor. 2014. Assigning unknown parent groups to reduce bias in genomic evaluations of final score in US Holsteins. J. Dairy Sci. 97:5814-5821. https://doi.org/10.3168/jds.2013-7821.

Tsuruta, S., I. Misztal, and I. Strandén. 2001. Use of the preconditioned conjugate gradient algorithm as a generic solver for mixed model-equations in animal breeding applications. J. Anim. Sci. 79:1166-1172. https://doi.org/10.2527/2001.7951166x.

Tyrisevä, A.-M., E. A. Mäntysaari, J. Jakobsen, G. P. Aamand, J. Dürr, W. F. Fikse, and M. H. Lidauer. 2018. Detection of evaluation bias caused by genomic preselection. J. Dairy Sci. 101:31553163. https://doi.org/10.3168/jds.2017-13527.

Van Grevenhof, E. M., J. A. M. Van Arendonk, and P. Bijma. 2012. Response to genomic selection: The Bulmer effect and the potential of genomic selection when the number of phenotypic records is limiting. Genet. Sel. Evol. 44:26-35. https://doi.org/10.1186/ 1297-9686-44-26.

VanRaden, P. M. 2008. Efficient methods to compute genomic predictions. J. Dairy Sci. 91:4414-4423. https://doi.org/10.3168/jds 2007-0980.

Vitezica, Z. G., I. Aguilar, I. Misztal, and A. Legarra. 2011. Bias in genomic predictions for populations under selection. Genet. Res. (Camb.) 93:357-366. https://doi.org/10.1017/ S001667231100022X.

\section{ORCIDS}

S. Tsuruta ๑ https://orcid.org/0000-0002-6897-6363

T. J. Lawlor $\odot$ https://orcid.org/0000-0002-4458-1025

D. A. L. Lourenco @ https://orcid.org/0000-0003-3140-1002

I. Misztal $\odot$ https://orcid.org/0000-0002-0382-1897 